\title{
Health and social costs of tobacco use in Ontario, Canada, 1979 and 1988
}

\author{
Bernard C K Choi, Anita W P Pak
}

\begin{abstract}
Study objective - This study aimed to estimate the health and social costs of tobacco use in Ontario, Canada.

Design - This was a cost-benefit analysis based on cross sectional data in 1988, stratified by age and sex, using an attributable risk model. The total cost of the consequences of tobacco use in the society included those costs attributed to extra deaths, disability, hospitalisation, physician visits, and fire losses, from tobacco use.
\end{abstract}

Participants - The general population of Ontario, Canada.

Main results - The total cost of tobacco use in Ontario, Canada in 1988 was estimated to be $\$ 3.623$ billion - $\$ 721$ million more than the total consumer expenditure on tobacco products. Tobacco use was also found to be responsible for $14 \%$ of all adult deaths, $5 \%$ of all adult disability days, $14 \%$ of all days of hospitalisation, and $3 \%$ of all physician visits. Compared with previous results for Ontario (1979) the cost of the consequences of tobacco use had increased by about $25 \%$ and consumer expenditure by about $35 \%$ over the period, while the excess of consequences over expenditure fell slightly by about $3 \%$.

Conclusions - The annual excess of the social costs of tobacco use over total consumer expenditure is staggering. It is suggested that similar cost-benefit analysis of smoking be carried out at regular intervals to monitor smoking trends in the society, to estimate health and social costs, and to provide information for the setting of targets for tobacco control and healthy public policies.

Occupational and Environmental Health Unit, Department of Preventive Medicine and Biostatistics, Faculty of Medicine, University of Toronto FitzGerald Bldg, 150 College St, Toronto, Ontario, Canada M5S 1A8 B C K Choi

Department of Psychology, Brock University, St Catharines, Ontario, Canada A W P Pak

Correspondence to: Dr B C K Choi.

Accepted for publication July 1995

\section{( $f$ Epidemiol Community Health 1996;50:81-85)}

Tobacco is known to be associated with more adverse health consequences than any other single product, and these consequences are associated with a monetary cost for the society. ${ }^{1-4}$ Estimation of the health and social costs of tobacco use is increasingly regarded as important for providing information for the setting of targets for tobacco control strategies, such as raising taxes on cigarettes, ${ }^{5}$ "quit and win" contests, ${ }^{3}$ cessation programmes, ${ }^{67}$ and smoke free work environment. ${ }^{8}$

In 1984, Collishaw and Myers ${ }^{5}$ presented a method for cost-benefit analysis of tobacco use in Canada in 1979. This method was later applied to calculate the social costs and benefits of tobacco use for various regions within
Canada. ${ }^{910}$ Results obtained for Ontario (1979), Metropolitan Toronto (1983), and the City of Toronto (1983) were similar to those of Collishaw and Myers for Canada (1979). In all cases, the total cost of the consequences of tobacco use exceeded the total consumer expenditure for tobacco products.

Because the methodology developed by Collishaw and Myers $^{4}$ can be applied to different geographical regions to look at differences in the costs and benefits of smoking, we decided to use it to update the Ontario results and look at differences in the costs and benefits of tobacco use over time. This study was funded by the Ontario Ministry of Health in 1991. A review of the data available from various sources indicated that at the time of this study Ontario 1988 provided the most complete and timely data for this purpose. It is on these sources, therefore, that this present study has relied. Results for the Ontario 1988 study are also compared with those for Ontario 1979 to identify changes in the health and social costs of tobacco use over time.

\section{Methods}

The methodology for the cost-benefit analysis of the consequences of tobacco use has been described in detail in Collishaw and Myers. ${ }^{4}$ Improvement to the methodology of calculating the per capita annual costs and benefits has been described in Choi and Nethercott ${ }^{9}$ and Choi,${ }^{10}$ based on the suggestions of Thompson and Forbes. ${ }^{11}$

In this study, the population exposed to tobacco's risk included all current daily and occasional smokers of cigarettes, pipes, or cigars, and all former smokers who smoked for 10 or more years and quit fewer than five years ago, as defined in Collishaw and Myers. ${ }^{4}$ The following age groups were used: $15-24,25-34,35-44$, $45-54,55-64,65+$ years.

Data sources for the Ontario 1988 study are as follows:

(1) The percentages of the population exposed to tobacco's risk in relation to sex and age group for Ontario in 1988 were assumed to be the same as those for Ontario in 1981, the most recent data available. These were derived from Canada's labour force survey conducted in $1981 .^{12}$ Although the labour force survey was also conducted in 1986, start and quit dates were not included and therefore it was not possible to calculate the number of former smokers who smoked for 10 or more years and quit fewer than five years ago. The most recent year for which that information was available was 1981 . 
(2) The total numbers of deaths (all causes) in relation to sex and age group were obtained from unpublished tabulations from the Office of the Registrar General. ${ }^{13}$

(3) Present values of future income in millions of dollars in relation to sex and age group were derived from 1988 income data ${ }^{14}$ for Ontario, using the method described in Collishaw and Myers. ${ }^{4}$

(4) The total numbers of days of disability in relation to sex and age group for Ontario in 1988 were not available. These numbers were estimated by extrapolation of number of disability days in Ontario in 1979 obtained from the Canada health survey, ${ }^{15}$ using 1979 and 1988 sex and age specific Ontario population structures.

(5) Average daily incomes in relation to sex and age group were derived from Statistics Canada ${ }^{14}$ income distribution data for Ontario in 1988.

(6) Total numbers of days of hospitalisation for persons dead at time of separation (discharge from hospital) in relation to sex and age group for Ontario, 1988 were obtained from unpublished tabulations from Ontario Ministry of Health. ${ }^{16}$

(7) Total numbers of days of hospitalisation for persons alive at the time of discharge in relation to sex and age group were obtained from unpublished tabulations from the Ontario Ministry of Health. ${ }^{16}$

(8) Cost per day of hospitalisation data were obtained from the Ontario Ministry of Health's Hospital Statistics for $1987 / 1988 .^{17}$

(9) Total numbers of physician visits in relation to sex and age group were not available for 1988. These numbers were estimated by extrapolation of number of physician visits in Ontario in 1979 obtained from Canada health survey, ${ }^{15}$ using 1979 and 1988 sex and age specific Ontario population structures.

(10) Average cost per physician visit was obtained from the Ontario Ministry of Health (personal communication).

(11) Costs of fires attributable to tobacco use were calculated from property and forestry loss figures and fire protection cost figures provided by the Office of the Fire Marshal for

Table 1 Dollar estimates of the costs and benefits of tobacco use in Ontario in 1979 and in 1988 (in millions of 1994 Canadian dollars*)

\begin{tabular}{|c|c|c|}
\hline & $\begin{array}{l}\text { Ontario, } 1979 \dagger \\
(\%)\end{array}$ & $\begin{array}{l}\text { Ontario, } 1988 \ddagger \\
(\%)\end{array}$ \\
\hline $\begin{array}{l}\text { Consequences (costs) } \\
\text { Forgone income due to mortality } \\
\text { Partial income loss due to disability } \\
\text { Direct costs of hospitalisation } \\
\text { Direct costs of physician visits } \\
\text { Fire damage } \\
\text { Totals } ₫\end{array}$ & $\begin{array}{l}2181(75 \cdot 2) \\
131(4 \cdot 5) \\
513(17 \cdot 7) \\
47(1 \cdot 6) \\
28(1 \cdot 0) \\
2900(100 \cdot 0)\end{array}$ & $\begin{aligned} & 2607(72 \cdot 0) \\
& 178(4 \cdot 9) \\
& 666(18 \cdot 4) \\
& 99(2 \cdot 7) \\
& 72(2 \cdot 0) \\
& 3623(100 \cdot 0)\end{aligned}$ \\
\hline $\begin{array}{l}\text { Consumer expenditure (benefits) } \\
\text { Industry share } \\
\text { Federal tax } \\
\text { Provincial tax } \\
\text { Totals } \$\end{array}$ & $\begin{array}{r}1051(48 \cdot 8) \\
635(29 \cdot 4) \\
470(21 \cdot 8) \\
2156(100 \cdot 0)\end{array}$ & $\begin{array}{r}1051(36 \cdot 2) \\
909(31 \cdot 3) \\
943(32 \cdot 5) \\
2902(100 \cdot 0)\end{array}$ \\
\hline Excess of consequences over expenditure & 744 & 721 \\
\hline
\end{tabular}

* Dollar figures are inflated to 1994 levels using Consumer Price Index (CPI) figures. An inflator of $214.5 \%$ based $\mathrm{CPI}$ is applied to the 1979 Ontario data to convert them to 1994 Canadian dollars, and $125.7 \%$ is applied to convert 1988 dollars to 1994 values.

dollars, and $125.7 \%$ is applied to convert 1988 dollars to 1994 values. and Nethercott.

Dollar estimates for Ontario, 1988 are based on this study.

‡Dollar estimates for Ontario, 1988 are based on to to to rounding.
Ontario, 1986 (personal communication) the most recent data available at the time of study, by applying a consumer price index (CPI) inflator.

(12) Distribution of expenditure on tobacco was calculated from data provided by the Ontario Ministry of Revenue (personal communication) and Collishaw (personal communication).

Dollar figures from this study for Ontario, 1988 were inflated to 1994 levels using CPI figures. An inflator of $125.7 \%$ based on CPI was applied to the 1988 Ontario data to convert them to 1944 Canadian dollars. Also provided are dollar figures for Ontario, 1979 in 1994 Canadian dollars, calculated from the results of Choi and Nethercott ${ }^{9}$ using an inflator of $214.5 \%$ to convert 1979 to 1994 values.

\section{Results}

Table 1 shows the social costs and benefits of tobacco use in Ontario in 1979 and 1988, in millions of 1994 Canadian dollars. The cost of smoking in Ontario in 1988 was estimated to have totalled $\$ 3.623$ billion (1994 Canadian $\$$ ), about $\$ 721$ million more than the estimated total consumer expenditure for tobacco products ( $\$ 2.902$ billion). Among the costs for Ontario, 1988, forgone income due to premature mortality from tobacco use represented $72.0 \%$ of the total monetary costs, followed by direct costs of hospitalisation (18.4\%), partial income loss due to disability (4.9\%), direct costs of physician visits $(2 \cdot 7 \%)$, and fire damage $(2 \cdot 0 \%)$. The percentage distributions of costs in Ontario in 1988 and in 1979 were very similar (table 1). Among the social benefits for Ontario, 1988, the industry share represented $36 \cdot 2 \%$ of the total consumer expenditure, while federal and provincial taxes represented $31.3 \%$ and $32.5 \%$, respectively. Compared with Ontario, 1979, the industry share in the total consumer expenditure dropped from $48.8 \%$ (1979) to $36 \cdot 2 \%$ (1988) while the government share in the form of taxes increased (table 1).

It is necessary to adjust for the size of population of Ontario, which varies over time, in order to make a valid comparison of the Ontario 1979 and 1988 data. Table 2 gives the per capita cost and expenditure associated with smoking for Ontario in 1979 and in 1988. Al monetary values in table 2 have been adjusted to a baseline of 1994 Canadian \$. Comparing Ontario in 1988 with Ontario in 1979, using 1994 constant dollars, the per capita costs of forgone income due to mortality attributable to smoking increased from $\$ 335$ to $\$ 347$, the costs of disability increased from $\$ 20$ to $\$ 24$, direct costs of hospitalisation increased from $\$ 79$ to $\$ 89$, direct costs of physician visits increased from $\$ 7$ to $\$ 13$, and costs of fire damage increased from $\$ 4$ to $\$ 10$. The total consequences of tobacco use increased from $\$ 446$ per person in 1979 to $\$ 482$ per person in 1988, based on 1994 dollars. Comparing 1988 and 1979 , using 1994 constant dollars, the per capita expenditure for the tobacco industry decreased from $\$ 162$ and $\$ 140$, federa tax increased from $\$ 98$ to $\$ 121$, and provincial 
Table 2 Per capita* costs and benefits of tobacco use in Ontario in 1979 and in 1988 (in 1994 Canadian dollars)

\begin{tabular}{lcc}
\hline & Ontario, 1979 & Ontario, 1988 \\
\hline Consequences (costs) & & \\
Forgone income due to mortality & 335 & 347 \\
Partial income loss due to disability & 20 & 24 \\
Direct costs of hospitalisation & 79 & 89 \\
Direct costs of physician visits & 7 & 13 \\
Fire damage & 4 & 482 \\
Totalst & 446 & 140 \\
Consumer expenditure (benefits) & 162 & 121 \\
Industry share & 98 & 125 \\
Federal tax & 72 & 386 \\
Provincial tax & 332 & 96 \\
Totalst & 114 & \\
Excess of consequences over expenditure & &
\end{tabular}

* Population of Ontario age 15 years and above 6501600 in 1979 and 7516230 in 1988

† Items may not add up exactly to totals due to rounding.

tax increased from $\$ 72$ to $\$ 125$. Total consumer expenditure increased from $\$ 332$ per person in 1979 to $\$ 386$ per person in 1988 , based on 1994 dollars. These correspond to a per capita excess of consequences over expenditure of $\$ 114$ in 1979 and $\$ 96$ in 1988 , again based on 1994 dollars.

Table 3 shows that the extra burden on society due to the excess of consequences of tobacco use over expenditure in Ontario in 1988 remained high. The excess totalled $\$ 721$ million in 1988, which translates into an excess of $\$ 96$ per person. In 1979 , the excess was $\$ 744$ million ( $\$ 114$ per person). Our 1988 study indicates that totally eliminating tobacco use in Ontario for one year would have resulted in 9166 fewer deaths ( $13.5 \%$ of all deaths), $6 \cdot 1$ million fewer adult disability days $(4.9 \%$ of all disability days), 1.39 million fewer days of hospitalisation $(13.8 \%$ of all days of hospitalisation), and 0.75 million fewer physician visits $(2 \cdot 5 \%$ of all visits) (table 3$)$.

\section{Discussion}

The methodology of Collishaw and Myers ${ }^{4}$ has been applied to estimate the costs of tobacco use in Ontario in 1988 by assessing the monetary value of the consequences of tobacco use attributable to premature death, disability, hospital and medical costs, and fire damages. This methodology estimates the costs associated with premature deaths from smoking, which is similar to the concepts of years of life lost ${ }^{4}$ and decrease in life expectancy ${ }^{1218}$ used in other cost-benefit analysis models for tobacco. The attributable risk approach used in this study has also been employed in other studies on the economic costs of health effects of smoking. ${ }^{19}$ Medical care expenditure has also been suggested as an important component in costbenefit analysis. ${ }^{1219-22}$

Table 3 Extra burden on a society that can be removed by eliminating tobacco use in the society for one year

\begin{tabular}{|c|c|c|}
\hline & Ontario, 1979 & Ontario, 1988 \\
\hline $\begin{array}{l}\text { Total (and per capita) } \\
\text { excess of consequences over }\end{array}$ & $\begin{array}{l}\$ 744 \text { million } \\
\text { ( } \$ 114 \text { per person) }\end{array}$ & $\begin{array}{l}\$ 721 \text { million } \\
(\$ 96 \text { per person) }\end{array}$ \\
\hline $\begin{array}{l}\text { No (\%) deaths } \\
\text { No (\%) days of disability } \\
\text { No (\%) days of hospitalisation } \\
\text { No (\%) physician visits }\end{array}$ & $\begin{array}{l}7996(13 \cdot 4) \\
5 \cdot 00 \text { million days }(4 \cdot 8) \\
1.58 \text { million days }(14 \cdot 9) \\
0 \cdot 76 \text { million visits }(2 \cdot 9)\end{array}$ & $\begin{array}{l}9166(13 \cdot 5) \\
6.10 \text { million days }(4 \cdot 9) \\
1.39 \text { million days }(13 \cdot 8) \\
0.75 \text { million visits }(2 \cdot 5)\end{array}$ \\
\hline
\end{tabular}

In this study, the costs associated with tobacco use have been compared with the annual consumer expenditure on tobacco products in Ontario in 1988. It was found that in 1988 the consequences of tobacco use in Ontario totalled $\$ 3.623$ billion (1994 Canadian \$), while the consumer expenditure amounted to $\$ 2.902$ billion, showing an excess of $\$ 721$ million in consequences over consumer expenditure.

These estimates are likely to be conservative. As Collishaw and Myers ${ }^{4}$ and Choi and Nethercott ${ }^{9}$ have pointed out previously, a number of potential sources of underestimation exist. For example, there are now more heavy smokers than when the major studies of the relative risks of smoking were conducted. No consideration has been given to the effects of passive smoking. There may have been an underestimation of relative risks in the classic studies of the effects of tobacco use. The real costs of treating tobacco-related disease may exceed the average cost of hospitalisation. The discounts applied for future income lost and days of disability may be excessive. The costs of pharmaceuticals, fire fighting, extra ventilation, maintenance, depreciation, productive time lost, and extra fire and life insurance ${ }^{6223}$ have not been taken into consideration as no estimates of these costs are currently available. No estimates of costs in terms of decrements in the quality of life have been attempted. The "social costs", ${ }^{24}$ and "pain, fear and discomfort"18 of tobacco smoking have not been estimated. Last but not least, the costs associated with teratogenic effects of tobacco use, ${ }^{2526}$ such as low birth weight, have not been included.

Comparison of the Ontario 1988 results with our 1979 results $^{9}$ has revealed a number of changes. In 1979, the total consequences of tobacco use in Ontario was $\$ 2.900$ billion (1994 Canadian \$) and the consumer expenditure was $\$ 2.156$ billion, with an excess of $\$ 744$ million. In 1988 , the total consequences of tobacco use in Ontario was $\$ 3.623$ billion (1994 Canadian \$) and the consumer expenditure was $\$ 2.902$ billion, with an excess of $\$ 721$ million. Therefore, the costs of the consequences of tobacco use in Ontario increased from 1979 to 1988 by about $25 \%$, the consumer expenditure increased by about $35 \%$, while the excess of consequences over expenditure fell slightly by about $3 \%$. When adjusted for population growth, the per capita consequences of tobacco use in Ontario in 1979 was $\$ 446$ per person and the per capita consumer expenditure $\$ 332$, with an excess of $\$ 114$ per person. In 1988 , the per capita consequence of tobacco use in Ontario was $\$ 482$ and the per capita consumer expenditure $\$ 386$, with an excess of $\$ 96$ per person. The per capita costs of the consequences of tobacco use in Ontario increased by about $8 \%$ from 1979 to 1988 , the consumer expenditure increased by about $16 \%$, while the per capita excess of consequences over expenditure decreased by about $16 \%$.

The percentage of all deaths attributable to smoking, the percentage of disability days attributable to smoking, percentage of hos- 
pitalisation days attributable to smoking, and the percentage of physician visits attributable to smoking in 1988 were very similar to those in 1979. This is probably due to the very similar age and sex specific percentages of the Ontario population exposed to tobacco's risk for 1979 and 1988, since the 1988 data was assumed to be the same as the 1981 labour force survey data for lack of more recent data. With similar population smoking patterns in 1979 and 1981, and the same relative risks being used, the attributable risks were very similar. This led to the similarity in the patterns of premature deaths, disability, hospitalisation, and physician visits attributable to smoking for 1979 and 1988.

The increase in costs of smoking consequences in 1988 compared with 1979 (based on 1994 Canadian \$) was mainly due to a slight increase in the income level over inflation in the same period, and moderate increases in the cost per day of hospitalisation and in the average cost of physician visit over inflation in the same period. For example, the inflationary increase from 1979 to 1988 based on CPI was $96.5 \%$, while the cost per day of hospitalisation increased from $\$ 152$ (1979 dollars) in 1979 to $\$ 381$ (1988 dollars) in 1988 , an increase of $150 \cdot 7 \%$ which was well above the CPI increase.

Between 1979 to 1988 , the tobacco industry share stayed at $\$ 1.051$ billion (1994 Canadian $\$$ ). Furthermore, when growth in the population has been taken into account, the per capita tobacco industry share actually fell from $\$ 162$ to $\$ 140$. On the other hand, federal tax and provincial tax increased substantially, from a combined total of $\$ 1.105$ billion in 1979 to $\$ 1.852$ billion in 1988 , an increase by $67.6 \%$ after adjusting for inflation. In 1979, federal tax was responsible for $29 \cdot 4 \%$ of total consumer expenditure on tobacco products and provincial tax for $21.8 \%$. In 1988 , federal tax was responsible for $31.3 \%$ and provincial tax for $32.5 \%$. This rather large increase in federal and provincial taxes was the main reason for the observed decrease in the excess of consequences over expenditure between 1979 and 1988.

A continuing increase in federal and provincial taxes for tobacco products is deemed to be necessary and beneficial to the society for a number of reasons. Economically, it increases the monetary value of the benefits to society of tobacco use in order to balance or even overstep the total costs of consequences of tobacco use in the society. Epidemiologically, the increase in tobacco taxes will lead to a reduction in the percentage of the population exposed to tobacco's risk, and therefore a reduction in premature deaths, disability, hospitalisation, and physician visits. Environmentally, a decrease in the percentage of the population who smoke will lead to a fall in fire damage to properties and forests, resulting in a cleaner environment. Burns ${ }^{6}$ also suggested using new cigarette taxes to help fund reform in health care in the US, especially for the 37 million uninsured people, to decrease the cost of health care for employers and the society, and to force more smokers to quit. Based on this study using 1988 Ontario data, it seems that federal and provincial taxes will have to be increased by approximately another $40 \%$, from the 1988 amount of $\$ 1.852$ billion (1994 $\$$ ) to $\$ 2.573$ billion, in order to balance out consumer expenditure and costs of consequences.

The results of this study indicate that the potential impact that could be made through elimination or reduction in the use of tobacco products is enormous. Had tobacco use been eliminated completely for just one year in Ontario in 1988, there would have been a saving of 9166 lives (including 7413 men and 1753 women who otherwise would have died of tobacco related diseases), and elimination of $6 \cdot 10$ million days of disability, 1.39 million days of hospitalisation, and 750 thousand physician visits. This is about $14 \%$ of all deaths, $5 \%$ of all disability days, $14 \%$ of all hospitalisation days, and $3 \%$ of all physician visits.

This discussion of the health consequences of smoking may give the impression that if smoking were eliminated, the direct health costs of tobacco related diseases would also be eliminated. It must be acknowledged that these health costs may be incurred by the same individual, at a later age, by disability or morbidity from causes other than smoking. For example, Leigh and Fries ${ }^{27}$ estimated the health care costs associated with "unhealthy" habits such as cigarette smoking, excessive drinking, excess body mass, and lack of exercise and seat belt use, among a group of 1558 senior citizens and retirees. These habits were found to be associated with roughly $\$ 372$ to $\$ 598$ of direct costs and $\$ 4298$ of total costs per person per year. Therefore, there is a potential source of overestimation of the costs attributable to tobacco use in our study. However, for the sake of parsimony, when discussing the health consequences and direct health costs of tobacco use, it is necessary to consider tobacco related diseases in isolation, rather than in conjunction with other non-tobacco related diseases.

This study indicates that cost-benefit analysis can provide important information for public policy on tobacco use. Our previous study ${ }^{9}$ indicated that the methodology developed by Collishaw and Myers ${ }^{4}$ can be applied to different geographical regions to look at geographical variations in the cost-benefit consideration of tobacco use. This study indicates that the methodology can be applied to different times to look at variations over time in the costbenefit consideration of tobacco use. It is suggested that in the future, the percentage of the population exposed to tobacco's risk should be closely monitored, perhaps annually through community health surveys. Once the percentage of tobacco exposure is obtained, the other necessary data for input to the mathematical model, including annual number of deaths, future income, disability days, average daily income, days of hospitalisation, cost per day of hospitalisation, number of physician visits, cost per visit, cost of fire damage, tobacco industry share, and federal and provincial taxes, can be obtained through searching existing data sources. In this case, the methodology proposed in this paper can be repeated over time, perhaps 
every year, to monitor smoking trends in the population, to estimate the health and social costs of smoking, and to provide important information for setting healthy public policies.

This study was supported in part by the Ontario Ministry of Health Contract no HPB 90-20, and by a computer grant to D B C K Choi from the Cancer Research Society. The authors thank the Health Promotion Branch, Ontario Ministry of Health, for carrying out data collection for the 1988 study. The 1979 study was supported by a grant from the Metropolitan Toronto District Health Council.

1 Lippiatt BC. Measuring medical cost and life expectancy ippiatt BC. Measuring medical cost and life expectancy impacts

2 Hodgson TA. Cigarette smoking and lifetime medical expenditures. Milbank $Q$ 1992;70:81-125.

3 Tillgren P, Rosen M, Haglund BJ, Ainetdin T, Lindholm $\mathrm{L}$, Holm LE. Cost-effectiveness of a tobacco 'quit and win' contest in Sweden. Health Policy 1993;26:43-53.

4 Collishaw NE, Myers G. Dollar estimates of the consequences of tobacco use in Canada, 1979. Can f Public Health 1984;75:192-199.

5 Burns J. Use new cigarette taxes to help fund reform. Business and Health 1993;11:6.

6 Weiss SJ, Jurs S, Lesage JP, Iverson DC. A cost-benefit analysis of a smoking cessation program. Evaluation and Program Planning 1984;7:337-46.

7 Swank RT, Becker DM, Jackson CA. The costs of employee smoking. A computer simulation of hospital nurses. Arch smoking. A computer simulatic
Intern Med 1988;148:445-8.

8 Nixon JC, West JF. Cost reductions from a smoking policy. Employee Benefits fournal 1989;14:26-30.

9 Choi BCK, Nethercott JR. The economic impact of smoking in Canada. International fournal of Health Planning Management 1988;3:197-205.

10 Choi BCK. A cost-benefit analysis of smoking in Canada. Research in Human Capital Development 1993;7:149-75.

11 Thompson ME, Forbes WF. Reasons for the disagreements on the impact of smoking on medical care expenditures:
A proposal for a uniform approach. Soc Sci Med 1985;21: $771-3$.

12 Health and Welfare Canada. Health Services and Promotion Branch, Health Promotion Directorate. Canada's labour Branch, Health Promotion Director
force surveys 1981 and 1986, 1990.

13 Ontario Ministry of Health. Community Information Section. Office of the Registrar General, unpublished tabulations, 1990

14 Statistics Canada. Income distribution by size in Canada, 1988. Statistics Canada Catalogue 13-207. Ottawa: Statistics Canada, 1989

15 Statistics Canada. Department of National Health and Welfare, Research and Analysis Section. Canada health survey. unpublished tabulations, 1983.

16 Ontario Ministry of Health. Community Information Section HMRI separations file unpublished tabulations, 1990.

17 Ontario Ministry of Health. Hospital statistics 1987/1988, Toronto: Ministry of Health, 1988.

18 Schelling TC. Economics and cigarettes. Prev Med 1986; 15:549-60.

19 Rice DP, Hodgson TA, Sinsheimer P, Browner W, Kopstein AN. The economic costs of the health effects of smoking, 1984. Milbank $Q$ 1986;64:489-547.

20 Leu RE, Schaub T. Does smoking increase medical expenditure? Soc Sci Med 1983;17:1907-14.

21 Vogt TM, Schweitzer SO. Medical costs of cigarette smoking in a health maintenance organization. Am $\mathcal{f}$ Epidemio 1985;122:1060-6.

22 Stoddart GL, Labelle RJ, Barer ML, Evans RG. Tobacco taxes and health care costs. Do Canadian smokers pay their way? $\mathcal{F}$ Health Economics 1986;5:63-80.

23 Penner M, Penner S. Excess insured health care costs from tobacco-using employees in a large group plan. $\mathcal{f}$ Occup Med 1990;32:521-3.

24 Markandya A, Pearce DW. The social costs of tobacco smoking. Br f Addict 1989;84:11 39-50.

25 McParlane EC, Mullen PD, DeNino LA. The cost effectiveness of an education outreach representative to $O B$ practitioners to promote smoking cessation counseling Patient Education and Counseling 1987;9:263-74.

26 Adams MM, Brogan DJ, Kendrick JS, Shulman HB, Zahniser SC, Bruce FC. Smoking, pregnancy, and source of prenatal care: Results from the pregnancy risk assessment monitoring system. Obstet Gynecol 1992;80:73844.

27 Leigh JP, Fries JF. Health habits, health care use and costs in a sample of retirees. Inquiry 1992;29:44-45. 